\title{
NATURE-INSPIRED DESIGN FOR SELF-ORGANIZED SOCIAL SYSTEMS: A TOOL FOR COLLABORATIVE COMMUNITIES
}

\author{
Lee, Sumin (1); Baek, Joon Sang (2) \\ 1: Ulsan National University of Science and Technology; 2: Yonsei University
}

\begin{abstract}
This research was motivated by the need to design for self-organized and sustained collaborative communities. A collaborative community is defined as a group of people who are bound by a sense of community and fulfil their unmet needs through collaboration (Baek, Meroni, \& Manzini, 2015). A community with limited resources and premature organisational structure and therefore experience an unbalanced workload is fragile. If the community fails to distribute workloads fairly within and the commitment of the sacrificing members is exhausted, it is likely to fall apart. Inspired by the selforganization phenomena in nature, we designed a tool that these communities can use to conceive strategies that contribute to autonomy and collaboration. For validation, we applied the tool to an industrial design student club. The results demonstrate that despite the differences between social and ecological systems, there is a potential to learn from nature to design for self-organized collaborative communities with the condition that one has sufficient knowledge about both the references and the design target. We also discuss the problem-solving and learning effects of the tool.
\end{abstract}

Keywords: Self-organization, Bio-inspired design / biomimetics, Design methodology, Participatory design, Organizational processes

\section{Contact:}

Baek, Joon Sang

Yonsei University

Department of Human Environment and Design

Korea, Republic of (South Korea)

joonsbaek@gmail.com 


\section{INTRODUCTION}

Collaborative community is a group of people who are actively and voluntarily engaged in the collaborative production of solutions to their own social problems, and in doing so, create a positive impact on society as a whole. These solutions are called collaborative services (Baek et al., 2015). Its notion originates from the studies that investigated grassroots social innovation practices and modelled design interventions for them (Meroni ed. 2007; Jegou and Manzini, 2008). In our study, however, we use this term in a more general context to describe communities whose primary activity is characterized as collaboration. A collaborative community may get into trouble when it lacks autonomous participation of its members and is driven by a few core members who take charge of most tasks and, as the result, feel excessive pressure. For instance, Ahop, a student-run industrial design club was suffering from a lack of enthusiasm and determination with low sense of goal among its members. Ahop was formed by design majoring students at UNIST (Ulsan National Institute of Science and Technology) with a mission to train design skills and build convivial relationships through collaborative projects. As of 2017, there were nine members involved in design projects individually or as a team. Overall, they lacked enthusiasm and determination with a low sense of goal, and as the result, the leader was challenged to run collaborative projects and felt the burden and pressure of continuing the club activities.

Self-organisation

Self-organisation is defined as a phenomenon that forms structures at the global level of a system through interactions at the lower level. The components at the lower level interacts with local environments or neighbours so that the complex pattern at the global level can appear without global control or leader, presenting an emergent property of the system (Camazine et al., 2003). Nature is the most abundant source of self-organisation with examples such as honey bees finding food, fish schooling, and ants building walls and trails. Self-organisation is characterized as having the dynamic system, emergent properties, multistate system, and complexity with simple rules. It is composed of (1) rules of the system, (2) system members, (3) members' functions, (4) direct interactions between members, and (5) indirect interactions that medium the environment (Ibid.). Self-organisation is also widely observed in human society such as the pedestrians walking on the shortest path to destination without colliding with others (Moussaïd et al., 2011) or a flash mob campaign where people voluntarily gather and spend money to support a sustainable business (Carrotmob, 2018). We argue that we can learn from the concept and mechanism of various self-organisation cases in nature to design for more self-organised communities.

\section{Biomimicry}

Biomimicry (or biomimetics) is the part of science that explore the opportunities of being inspired by nature's models including designs and processes or imitating them to solve human problems (Benyus, 2002). Benyus argued that the problems we strive to solve have already been solved in the process of 3.8 billion-year evolution, and there is much to learn from biologic systems for innovative and sustainable development. Numerous cases of nature-inspired design exist at the level of the form and function (Ibid., Mead, 2014, Vukusic and Barr, 2010). For example, Japan Railways West designed the shape of a highspeed train by looking at the beak of a fast-moving water pistol, and a company called Sharklet Technologies developed a bacterial-free skin texture inspired by the wall of a Galapagos shark. Regen company paid attention to the process of food foraging by ants or bees at the group level and developed an algorithm that minimize peak power usage by household appliances. Inspired by photosynthesis, OneSun developed a solar cell that is very inexpensive and rechargeable every five years (Benyus, 2002).

However, studies on or practical cases of nature-inspired information systems to support human collaboration remain scarce. Among these rare studies is the study by Christensen (2014) who has introduced stigmergy, a concept initiated by entomologists to explain the cooperation mechanism of termites, to the computer-supported cooperative work (CSCW) field. Notwithstanding the differences between human society and ecosystem (Holbrook et al., 2010), we question the possibility to be inspired by the self-organisation of nature in designing for collaborative communities and address the following research questions: (1) Can we learn from nature to design for self-organisation considering the differences between them? (2) (How) does self-organisation in nature inspire the design for collaborative communities? To address these questions, we conducted the systemic literature reviews, developed a nature-inspired design tool and applied it to a student club for validation. 


\section{LITERATURE REVIEWS}

\subsection{Objectives and methods}

We used the systematic literature reviews to identify the existing works that apply nature-inspired design to the social systems design and especially self-organisation, to explore whether selforganisation in nature has the potential to inspire to design for collaborative services despite the basic difference between nature and human society, and to identify the gaps in current research. The literature was searched in six data bases: Google scholar, Proquest, Science direct, Scopus, Scientific, Web of science. Searching keywords were 'nature-inspired', 'bio-inspired', 'biomimicry', 'selforganisation', 'organisation design', 'tool design' etc. Firstly, we sorted out 140 potentially related papers based on the title among searching results. They were rated into 1 to 5 scales depending on relevance to the topic with abstracts and keywords. There were thirty-nine papers, which was ranked as 5, with the most relevant topic. Among them, nineteen fit the purpose of this paper.

\subsection{Results}

Mead (2014) reports that compared with biomimicry and nature-inspired design studies of tangible products, engineering and robotics, those of organisations and systems are relatively few. Among those we found were bio-inspired design applied to the development of agent systems (Serugendo et al., 2005), industrial networks design (Layton et al., 2016), and system network design (Yeom, 2009). Previous works of bio-inspired organisations and systems design include the 'Images of organisations' (Morgan, 2006) which applied biological models to organisational theory, the 'Keystone Advantage in Microsoft and WalMart' (Mead, 2014), 'Creating a niche in which they are the keystone species' (Iansiti \& Levien, 2004b), and 'Swarm theory to management techniques' (Bonabeau \& Meyer, 2001) (Mead, 2014).

There were also several studies that apply self-organisation to (organisational) systems design: Michlmayr (2006) used the algorithm of ant colony to design peer-to-peer network system. Toni and colleagues (2012) investigated self-organisation of open innovation web-based platform. Serugendo (2007) applied the principal of self-organisation and emergence into the agent system development. There are cases that utilized self-organisation for management or work force system, while foregoing studies mostly deal with self-organisation in network, agent system. Molleman (1998) explained selforganisation in human resource management, and Shukla and Sinclair (2010) examined selforganisation strategies as community-based conversation initiative. Smith and Comer (1994) demonstrated the usefulness of applying self-organisation to small group. Mahmud (2009) studied the application of self-organisation concept in natural science to enterprise management and communication. However, there was a lack of methodological studies that help designers apply natural principles such as self-organisation to social systems design (Kim \& Baek, 2015) despite the need for designers in the field of bio-inspired organisational design (Kennedy et al., 2015). Based on the literature studies, we propose a tool to design for self-organised social systems inspired by nature.

\section{METHOD}

\subsection{A Tool to design for self-organised social systems inspired by nature}

\subsubsection{Design}

This tool aims to help members of collaborative community identify their problems and devise solutions through a workshop session. The anticipated result is a set of simple rules just as how selforganisation works in nature. The tool was developed based on the cases in biological system. Among the examples introduced by Camazine and colleagues (2003), ten representative cases were referenced in the tool. The cases were then categorized thematically based on their implications to organisational goal, which is expected to help the users narrow down the references for application.

The tool consists of introduction, guideline book, case cards, worksheet, and inspiring sheets. The introduction booklet provides a comprehensive overview of the tool including its aim, concept, process, and expected results. It helps users understand the definition, principles and characteristics of self-organisation with illustrations and examples. It also explains how the tool is constructed and used (Figure 1-a). The guideline booklet explains in detail the process of using the tool so that users can 
follow its step-by-step instructions during the workshop. The factors user should consider at each stage are written in the form of questions or requests (Figure 1-b). Case cards introduce each case respectively. 10 cases are categorized with principles and grouped with colours. There is each description for the case and illustration on the front side and each principle on the back side. Users can refer the basic mechanisms or the details for each case (Figure 1-c). Inspiring sheets are the question sheets that help the translation process from nature cases to human cases. There might be difficulties to apply nature cases to human society directly. Inspiring sheets help user brainstorm solution ideas more easily by providing the flow of thinking (Figure 1-d). Worksheet is the part that will be the final result of the workshop. During the workshop, users either fill the worksheet with results from each step or attach notes written to the post-it. Worksheet includes the name, characteristics of the target organisation, design goals, design problems, and ideation results (Figure 1-e).

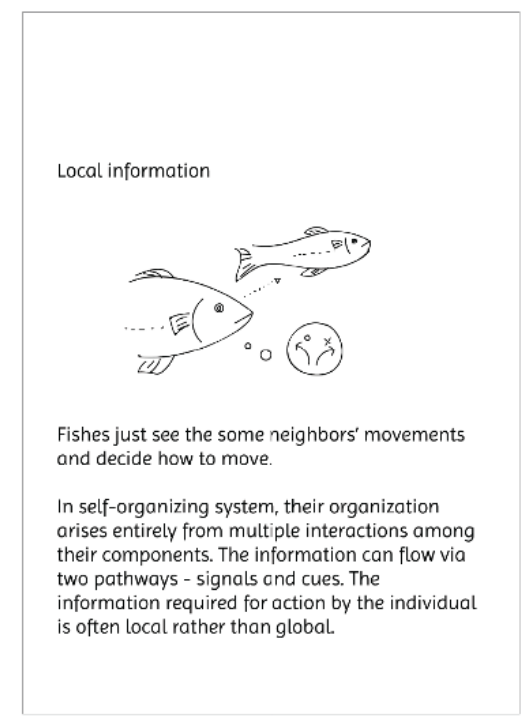

a. Introduction

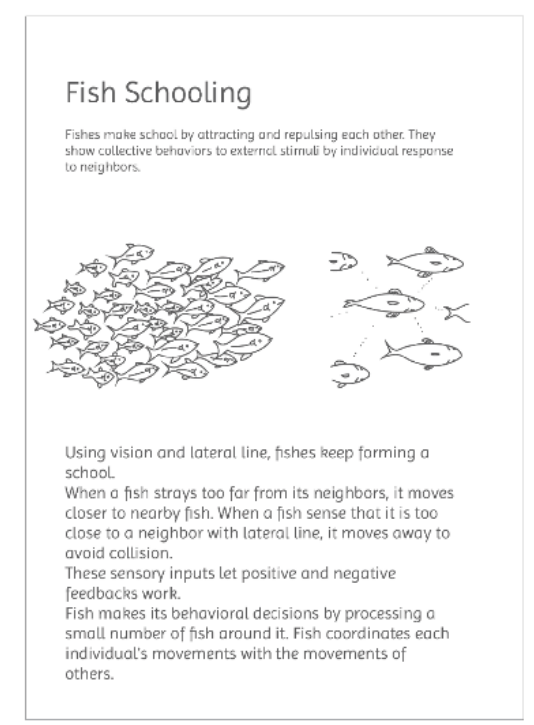

d. Case card (left: front side, right: back side)

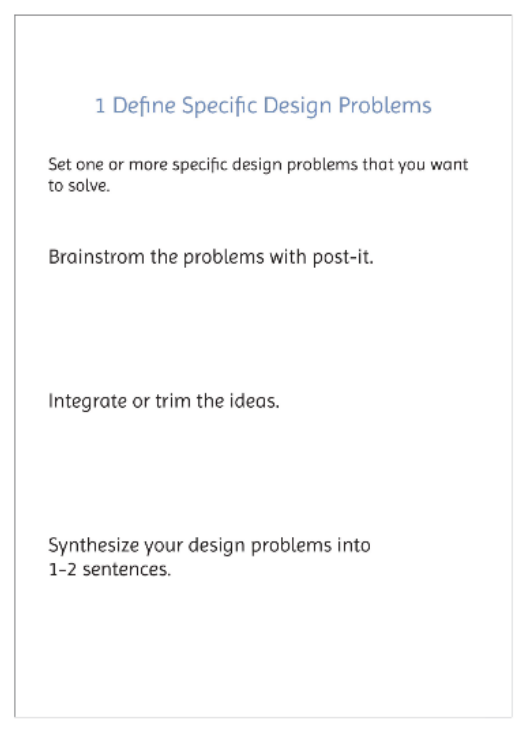

b. Process card

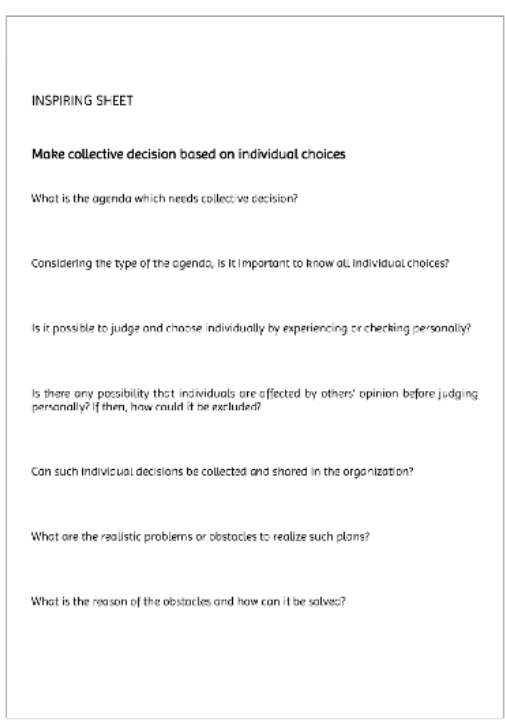

c. Inspiring sheet

\section{Maximize the effect by synchronizing}

\section{Fish Schooling}

Using information from sensory input, fish keeps constant size of school with positive and negative feedback. In addition they can disturb the predator by responding to neighbors. 


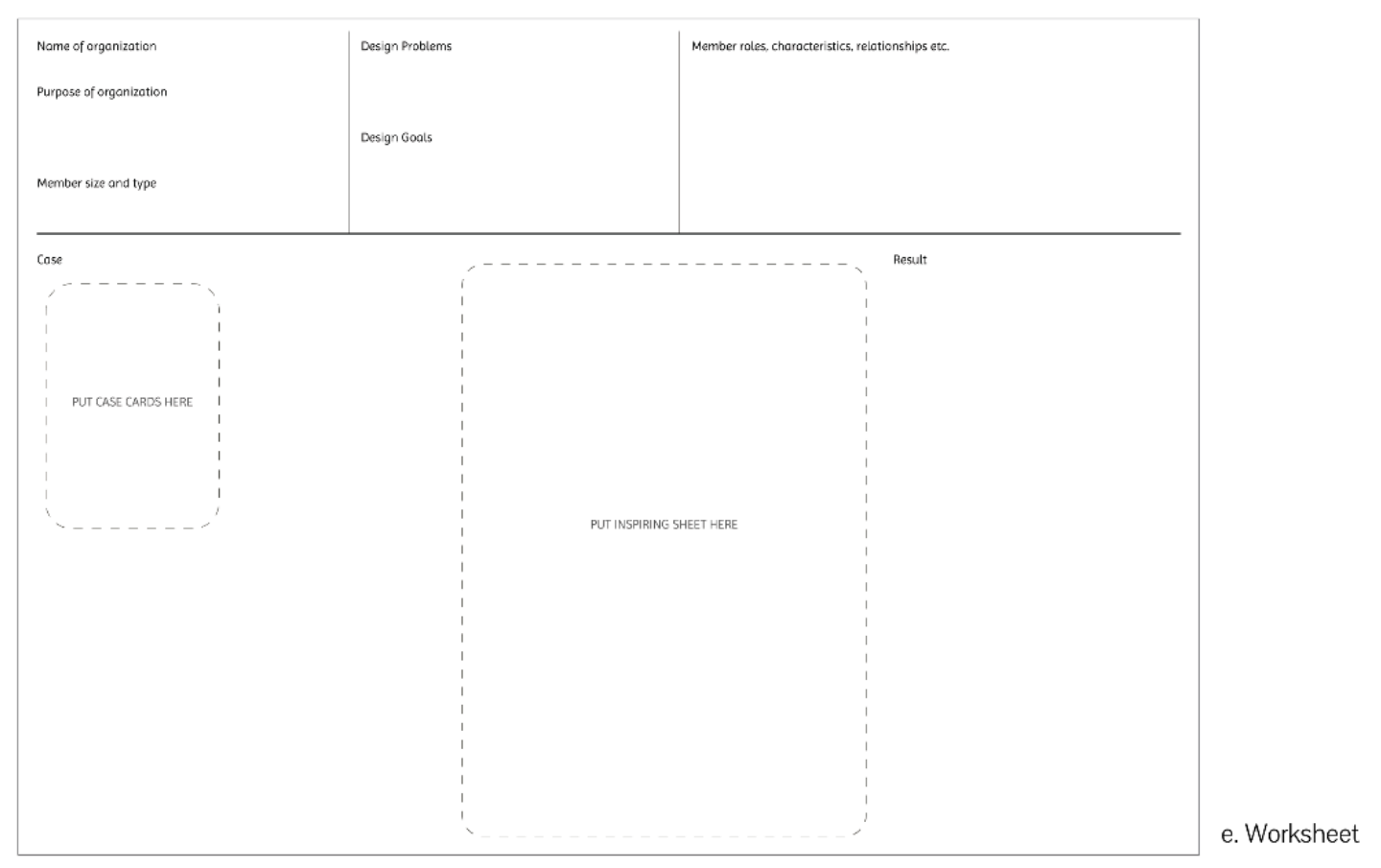

Figure 1. Tool components

The workshop consisted of design process in which users utilize the tool to tackle the problem they brought. The design process is as follows:

1. Describe your design background including the organisational goal, and the type and number of members. It is a step that defines and describes specific target organisation before dealing with problems.

2. Define specific design problems: Establishing specific problems that target organisation currently wants to address. Workshop participants will write their thoughts on the post-it and then decide on the issues that will ultimately be addressed in this workshop after classifying, integrating and removing them. It is similar to the affinity diagram process. This stage is to select one of the problems to manage with this workshop.

3. Define design goals: Participants establish the design goals they want to achieve. Then set goals for design problems described above.

4. Select the category of the problems to solve. These categories are: make collective decision based on individual choices, follow the decision selected by the majority, group benefit via individual actions for themselves, maximize the effect by synchronizing, forming structure according to specific template that changes along to condition, and response properly according to the result so far.

5. Select the cases and read: Each case card has a corresponding category on the back. Participants read cases corresponding to the categories they select.

6. Brainstorm ideas: answering the inspiring sheets that correspond to each category, participants proceed with the ideation for problem resolution. Participants can share ideas with each other by writing them on the post-it.

7. Finalize ideas: Combining and drawing up ideas. The ideas are summarized into a few simple rules. Participants share opinions and select and specify the final idea.

\subsection{Application}

We conducted a workshop with the student design club, Ahop, to validate the tool. Two students who served as the former presidents participated in a two-hour workshop to define the problem and generate self-organisation strategies (Figure 2). They have belonged to the club for more than a year. During the workshop, each participant received a tool set and used it to generate self-organisation strategies. The workshop was followed by an in-depth interview to discuss and reflect the workshop process and results. During the interview, the participants evaluated the feasibility of their own ideas and discussed a future plan for implementation. They also evaluated the effectiveness of the tool and 
the workshop and addressed the issues including the usability of the tool, usefulness in problem solving, and suggestions for improvement.

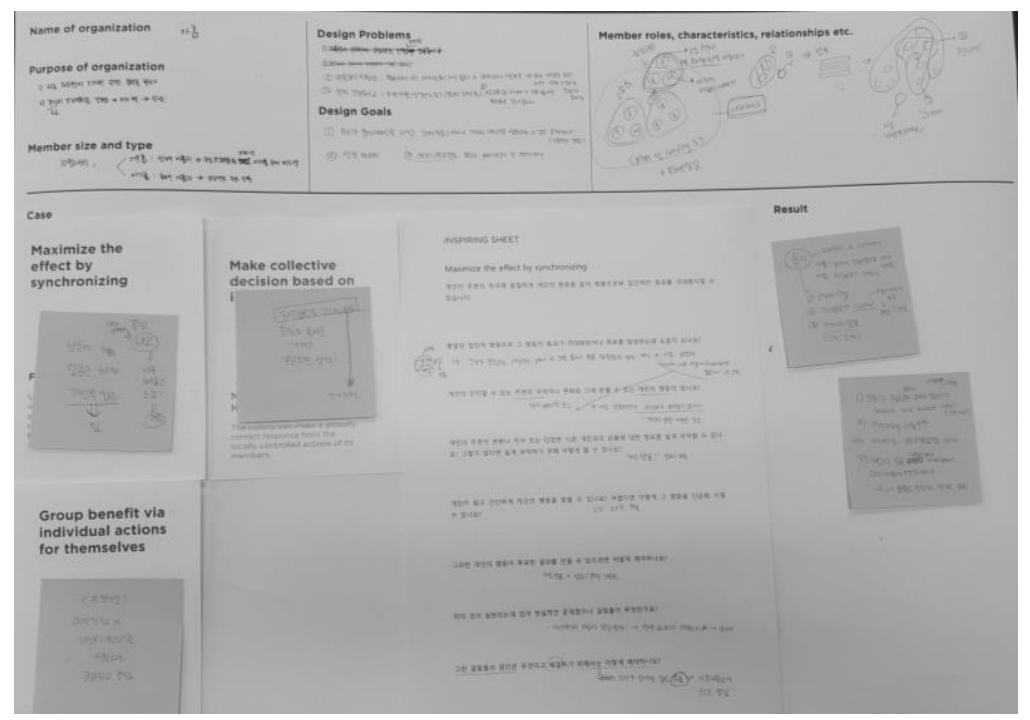

Figure 2. A sample worksheet generated from the workshop

\section{RESULT}

Participant A defined the organisational goal as building a club to fulfil the members' needs by supporting them to learn from one another and undertake collaborative design projects. The problem she raised was a misalignment between the collaborative project themes and individual interests, and thus looked for ways to enhance members' engagement in the projects. She selected as the reference cases the 'bark beetles' larvae: group benefit through ego-centric actions' and 'termite mound: structure forming based on a specific and dynamic template'. Bark beetles' larvae live on living trees and eat their tissue. The host tree produces the resin which has toxicity to kill the larvae, but the insects respond to this by secreting the aggregation pheromone that converts the compound into less harmful derivatives. Furthermore, the pheromone has the effect to attract other larvae which then make a joint effort to react to the resin and increase their chance to survive. The bark beetles' larvae case has an implication to the club Ahop that having one's own behaviour for sake of oneself act as a benefit for the group will help attract their participation, even if everyone is busy with their personal schedules. With this regard, the participant presented two ideas: firstly, to organise open sessions on a regular basis where each member reports her individual accomplishment to the others. This could encourage the members to stimulate and motivate one another. The second idea was to change the president's term of office from one year to one month. One of the responsibilities of the president is to lead collaborative projects and nurture the team spirit. By exposing all members directly to the leadership and responsibility in operating the club, they could participate in group activities with a greater awareness and empathy even when they are not leaders.

A queen termite has a large abdomen which continues to grow throughout her life. Termites thus construct a chamber whose size also grows over time in response to the queen's body. for the queen, and as her body size continues to grow, they rebuild the room again and again following a template. Note that, the participant had taken a role of president before.

Participant B was interested in the idea of influencing members' behaviour using a template or guidelines and suggested an idea to develop structured guidelines for organising group activities, which would make it easier for the members to conceive and engage in group activities and consequently lower the barrier to actively participate in the group projects.

Participant B defined the purpose of the group as helping each other with design-related studies, each working on team projects and receiving feedbacks to complete them. She defined the problems as follows: (1) the members lack commitment and enthusiasm to work autonomously in collaborative projects; (2) as the result, the projects progress rather slowly and involuntarily; and (3) the projects need to be more focused in topic in order to accumulate expert knowledge and build an identity. Hence the workshop goals were twofold: to create an ownership within the club by convincing each member 
of the benefits of participating in club activities, and to build the club identity through more focused project themes with an executive plan. She selected the following three cases as references: the bark beetles' larvae, fish schooling, and honeybees' nectar selection. She suggested that the collaborative projects should be recognized as an exercise to build a career as a designer and not just another assignment. Just as the larvae secrete the pheromone to aggregate and neutralize the toxin, senior members could help junior members overcome negative thoughts such as lack of confidence and scepticism during difficult times. This included giving verbal advice as well as sharing one's design portfolio. Fish schooling is a case of fish moving around depending on their neighbours or their external environment. Inspired by this phenomenon, the participant suggested that the members regularly share their progress so that they could compare their performance with the other's and make an adjustment if necessary. She hoped that in doing so the members could have an overview of how everyone is progressing and be stimulated by one another. She also emphasized that one's performance should be evaluated not in comparison with another's but based on the personal development plan. In the case of honey bees' nectar collection, the workers collectively select the food source according to individual's own decision. Based on this example of democratic collective choice, participants presented solution related to selecting project topics. Traditionally, when someone presents project topics arbitrarily, most takes them without clear criteria. As a result, many members cannot really be engaged in the project because they don't have enough interest in the topic. Participants suggested to set a long search period for selecting a topic and any item of interest to the members should be examined in detail rather than jump-in immediately without research. It is difficult to experience the subject in person right away, but at least members can check the details through research and investigation. For example, if one chooses a subject for a study group, one may find out what to study, whether there is a possibility to run the group, and analyze the book more closely. If they plan to open a flea market, they can consider what they will make based on customer needs as well as the materials and manufacturing processes available to them. Each investigation can be undertaken freely and independently, and information can be shared if necessary. In addition, based on the survey results, members with a common interest can be recruited by appealing the subject to them. She also acknowledged that this new democratic approach may require more time to implement than the traditional one.

To implement this idea, the participant suggested to form groups of three with mixed design experiences and have projects run in group. Each group investigates what topic to work on, makes an executive plan, and implement it. An individual project is also possible as before. This would practically reshuffle the existing group configuration, and the students would have a chance to interact with different people for each project. Within the group they would meet regularly to share the process, report the progress, and provide feedbacks to each other.

12 months later, we had an unstructured interview with the first participant who had implemented some of her ideas in the club. She reported that the ideas did not go as first planned. Related to the guidelines for organising group activities, she developed a template and shared it with other members only to find that people did not use it as much as she had expected. She also organised open progress report sessions with an aim to have the members stimulate one another, but this also did not make a big difference. She mentioned that the acceptance of her ideas in the club might have been limited due to her position as a member; if she had tried them as the president or an executive member, the results might have been different. In addition, the club had also adopted the monthly presidentship where the members took the role of president on a monthly basis. However, there was not a significant change in the way the projects ran compared to the conventional system. She speculated that as the term was shortened so was the responsibility of the president. They then tried a system where the annual and monthly presidency ran in parallel. The only role of the annual president was to pressure the members to do the tasks assigned to them. As the result, the group activities ran more effectively and the (annual) president felt less pressure and stress than before.

The participant reflected that although the idea from the tool provided her with a framework for organisational thinking, i.e. the principles and mechanisms of self-organisation provided her with a perspective to understand problems and brainstorm interventions related to the social systems design. We conclude from our short-term evaluation that our nature-inspired design for self-organisation provided the users with an opportunity to pay more attention to the design for self-organisation, diagnose organisational issues, and generate ideas to address them. Our findings align with previous 
studies that the acceptance of new ideas involves a process of adaptation to the old system (Junginger, 2015) and is influenced by the power and authority of the designer (Lofthouse \& Stevenson, 2013).

\section{DISCUSSION}

From the literature reviews, we found the potential for us to learn from nature to design for selforganisation. Because of the difference between nature and human society, the abstraction process is required for inspiration. The tool we designed is aimed for use during the concept generation phase of a community service design process. It is categorized as an intuitive method in the design by analogy, for which it requires the knowledge about two related subjects: a profound understanding of the design problem - the unique characteristics of a target social system, and sufficient knowledge of the references - self-organisation phenomena in nature. In our tool, when the self-organisation cases are provided as an input for concept generation, one goes through the process of abstraction, which consists of understanding the principles and mechanisms of self-organisation and interpreting their implications to the targeting social system, before appreciating them as the source of inspiration (Badarnah \& Kadri, 2015). It was during this process that the participants experienced a cognitive overstretch. This finding aligns with Keshwani and colleagues' report (2013) that ideas inspired by nature were more novel than those generated using brainstorming, but also smaller in quantity and required more cognitive efforts than the latter. It also implies the need to reduce the cognitive gap between understanding nature and generating solution ideas. Difficulty in understanding the cases could be partly solved by utilizing more visual contents such as video clips and photos.

As the benefit of this tool, we noted a learning effect in addition to problem solving. During the interview, the participant reflected that the tool provided her with an opportunity to develop a framework for organisational thinking, i.e. the principles and mechanisms of self-organisation provided her with a perspective to understand problems and brainstorm interventions related to the social systems design. We conclude from our short-term evaluation that our nature-inspired design for self-organisation provided the users with an opportunity to pay more attention to the design for selforganisation, diagnose organisational issues, and generate ideas to address them. Our findings align with previous studies that the acceptance of new ideas involves a process of adaptation to the old system (Junginger, 2015) and is influenced by the power and authority of the designer (Lofthouse \& Stevensen, 2013). Besides, the tool can suggest the guideline for improvement of the idea even if the initial application is not successful enough as the participant mentioned in her interview.

Despite the potential of nature-inspired design for self-organisation, it remains a question to be explored what the inherent differences between social and ecological systems are, and what are their implications to this study. The empirical data suggests that one cannot directly translate natural phenomena to human organisations. Existing works also note that the principles and mechanisms in nature need to be redefined and reinterpreted to the context of a target social system (Comfort, 1994), and it requires appropriate consideration when applying concepts from the natural sciences to the social sciences (Mahmud, 2009). With this regard, application of our tool is positioned as the weak biomimicry (Blok \& Gremmen, 2016), i.e. biomimicry that which considers nature as a source of inspirations for creating of new ideas, as opposed to the strong biomimicry that deems the nature as a normative principle to copy and reproduce. This tool is appropriate for those who want to be inspired by nature and also acknowledge the fundamental differences between social and ecological systems. The application of the idea generated using the tool is influenced by the users' motivation and sense of responsibility. For successful application, it is necessary to make effort to strengthen their relationships and motivate them in advance.

\section{CONCLUSION}

Inspired by the self-organisation of nature, this study suggests a tool to help design the collaborative service for the collaborative community. For a variety of reasons, collaborative communities often do not work smoothly, and we wanted to get inspiration from natural phenomena for design for sustainable collaborative community. With literature review, it has been shown that there are still relatively few researches about nature-inspired application for organisational design. But there are ongoing attempts to do so at the same time. We also saw the lack and need of tools at the system level to help us get inspiration from such self-organised natural cases. Therefore, we have focused on selforganisation, a phenomenon that creates complex patterns with peripheral stimuli and changes and 
proposed a tool to help community design based on self-organised natural cases. This tool supports the iterative process of collaborative service including the process from analysis to design. It helps users identify problems and present solutions, referring to natural cases. For validation, we applied the tool to an industrial design student club, and concluded that (1) we can learn from nature to design for a collaborative community with the condition that one has sufficient knowledge about both the references and the design target; (2) in addition to the problem solving, this tool also had a learning effect by providing users with a framework of thinking in dealing with organisational issues, and (3) we need to acknowledge and explore the differences between social and ecological systems.

We acknowledge that our proposition of learning from nature to design for self-organised social systems is grounded on weak evidences considering the small amount of supporting literature and empirical data. As a future work, we would like to strengthen the argument by undertaking additional literature studies in the fields of self-organisation and collaboration in both human societies and ecosystems to find an intersection and define the conditions of nature-inspired design. In addition, we are applying the tool to additional collaborative communities, through which we expect to evaluate the usability and effectiveness of the tool in more diverse contexts.

\section{REFERENCES}

AskNature (2012), Innovative paths to energy efficiency: REGEN Energy [online], Available at: https://asknature.org/resource/innovative-paths-to-energy-efficiency-regen-energy/ [Accessed 18 Sep 2017]

Badarnah, L. and Kadri, U. (2015), "A methodology for the generation of biomimetic design concepts", Architectural Science Review, Vol. 58 No. 2, pp. 120-133. https://doi.org/10.1080/00038628.2014.922458

Baek, J. S., Meroni, A. and Manzini, E. (2015), “A socio-technical approach to design for community resilience: A framework for analysis and design goal forming”, Design Studies, Vol. 40 No., pp. 60-84. http://doi.org/10.1016/j.destud.2015.06.004

Baltas, G., Tsafarakis, S., Saridakis, C. and Matsatsinis, N. (2012), "Biologically Inspired Approaches to Strategic Service Design: Optimal Service Diversification Through Evolutionary and Swarm Intelligence Models", Journal of Service Research, Vol. 16 No. 2, pp. 186-201. http://doi.org/10.1177/1094670512468215

Benyus, J. M. (2002), Biomimicry: Innovation Inspired by Nature, Harper Perennial, New York.

Blok, V. and Gremmen, B. (2016), "Ecological Innovation: Biomimicry as a New Way of Thinking and Acting Ecologically”, Journal of Agricultural and Environmental Ethics, Vol. 29 No. 2, pp. 203-217. http://doi.org/10.1007/s10806-015-9596-1

Bonabeau, E. and Meyer, C. (2001), "Swarm Intelligence: A Whole New Way to Think About Business”, Harvard Business Review, Vol. 79 No. 5, pp. 106-114.

Camazine, S., Deneubourg, J.-L., Franks, N. R., Sneyd, J., Theraulaz, G. and Bonabeau, E. (2003), Self-Organization in Biological Systems, Princeton University Press.

Carrotmob (2008), Carrotmob [online], Available at: https://www.facebook.com/carrotmob/ [Accessed December 12th 2018]

Christensen, L. R. (2014), "Practices of stigmergy in the building process", Computer Supported Cooperative Work (CSCW), Vol. 23 No. 1, pp. 1-19. http://doi.org/10.1007/s10606-012-9181-3

Comfort, L. K. (1994), "Self-Organization in Complex Systems”, Journal of Public Administration Research and Theory, Vol. 4 No. 3, pp. 393-410. http://www.jstor.org/stable/1181895

Ekekwe, N. (2010), The Leadership Lessons of Ants [online], Available at: http://hbr.org/2010/10/business-lessonsfrom-the-ants [Accessed 2018]

Hasegawa, E., Ishii, Y., Tada, K., Kobayashi, K. and Yoshimura, J. (2016), "Lazy workers are necessary for long-term sustainability in insect societies", Scientific Reports, Vol. 6 No. http://doi.org/10.1038/srep20846

Holbrook, C. T., Clark, R. M., Moore, D., Overson, R. P., Penick, C. A. and Smith, A. A. (2010), "Social insects inspire human design", Biology Letters, Vol. 6 No., pp. 431-433. http://doi.org/10.1098/rsbl.2010.0270

Iansiti, M. and Levien, R. (2004a), "Strategy as Ecology”, Harvard Business Review, Vol. 82 No. 3, pp. 68-78.

Iansiti, M. and Levien, R. (2004b), The Keystone Advantage: What the New Dynamics of Business Ecosystems Mean for Strategy, Innovation, and Sustainability, Havard Business Press, Boston.

Jegou, F. and Manzini, E. (2008), Collaborative services: Social innovation and design for sustainability, Edizioni Poli. Design.

Junginger, S. (2015), “Organizational Design Legacies and Service Design”, The Design Journal, Vol. 18 No. 2 , pp. 209-226. https://doi.org/10.2752/175630615X14212498964277

Kennedy, E., Fecheyr-Lippens, D., Hsiung, B.-K., Niewiarowski, P. H. and Kolodziej, M. (2015), "Biomimicry: A Path to Sustainable Innovation", Design Issues, Vol. 31 No. 3, pp. 66-73. http://doi.org/10.1162/DESI_a_00339

Keshwani, S., Lenau, T. A., Kristensen, S. A. and Chakrabarti, A. (2013) "Benchmarking bio-inspired designs with brainstorming in terms of Novelty of design outcomes", the 19th International Conference on Engineering Design (ICED13), Seoul, Korea, Republic of, 19-23 Aug 2013. 
Kim, S. and Baek, J. S. (2015) "Potential of Nature-inspired Approach for Organisation Design in Product-service System", the 20th International Conference on Engineering Design (ICED15), Milan, Italy, 27-30 July 2015.

Layton, A., Bras, B. and Weissburg, M. (2016), "Designing Industrial Networks Using Ecological Food Web Metrics”, Environmental Science and Technology, Vol. 50 No. 20, pp. 11243-11252. http://doi.org/10.1021/acs.est.6b03066

Lenau, T. A., Keshwani, S., Chakrabarti, A. and Ahmed-Kristensen, S. (2015) "Biocards and level of abstraction", the 20th International Conference on Engineering Design (ICED15), Milan, Italy, 27-30 July 2015, pp. 177-186.

Lofthouse, V. A. and Stevenson, N. (2013) "Is the industrial designer's changing role improving their opportunities for responsible design practices?”, IASDR 2013: Consilience and Innovation in Design, Tokyo, Japan.

Mahmud, S. (2009), "Framework for the Role of Self-Organization in the Handling of Adaptive Challenges", Emergence: Complexity and Organization, Vol. 11 No. 2, pp. 1-14.

Mead, T. L. (2014b) "Biologically-Inspired Management Innovations", The XXV ISPIM Conference - Innovation for Sustainable Economy \& Society, Dublin, Ireland, 8-11 June 2014.

Michlmayr, E. (2006) "Self-Organization for Search in Peer-to-Peer Networks: The Exploitation-Exploration Dilemma”, Bio-Inspired Models of Network, Information and Computing Systems, Madonna di Campiglio, Italy, 11-13 Dec 2006, IEEE. http://doi.org/10.1109/BIMNICS.2006.361796

Miller, D. (2007), National Responsibility and Global Justice, Oxford University Press. http://doi.org/10.1093/acprof:oso/9780199235056.001.0001

Molleman, E. (1998), "Variety and the requisite of self-organization", International Journal of Organizational Analysis, Vol. 6 No. 2, pp. 109-131. https://doi.org/10.1108/eb028880

Morgan, G. (2006), Images of Organizations, Sage Publications.

Moussaïd, M., Helbing, D. and Theraulaz, G. (2011), "How simple rules determine pedestrian behavior and crowd disasters", PNAS, Vol. 108 No. 17, pp. 6884-6888. http://doi.org/10.1073/pnas.1016507108

Seeley, T. D. (2010), Honeybee Democracy, Princeton University Press, Princeton, NJ.

Serugendo, G. D. M., Gleizes, M.-P. and Karageorgos, A. (2005), "Self-organization in multi-agent systems", The Knowledge Engineering Review, Vol. 20 No. 2, pp. 165-189. http://doi.org/10.1017/S0269888905000494

Shukla, S. R. and Sinclair, A. J. (2010), "Strategies for Self-organization: Learning from a Village-level Communitybased Conservation Initiative in India”, The Journal of Human Ecology, Vol. 38 No., pp. 205-215. http://doi.org/10.1007/s10745-010-9301-y

Smith, C. and Comer, D. (1994), "Self-organization in small groups: A study of group effectiveness within nonequilibrium conditions", Human Relations, Vol. 47 No. 5, pp. 553-581. http://doi.org/10.1177/001872679404700505

Toni, A. F. D., Biotto, G. and Battistella, C. (2012), "Organizational design drivers to enable emergent creativity in web-based communities”, The Learning Organization, Vol. 19 No. 4, pp. 337-351. http://doi.org/10.1108/09696471211226699

Venkataraman, S. and Chakrabarti, A. (2010), "Investigating novelty-outcome relationships in engineering design", Artificial Intelligence for Engineering Design, Analysis and Manufacturing, Vol. 24 No. 2, pp. 161-178. http://doi.org/10.1017/S089006041000003X

Vincent, B. B., Bouligand, Y., Arribart, H. E. and Sanchez, C. E. (2002), "Chemists and the School of nature”, New Journal of Chemistry, Vol. 26 No. 1, pp. 1-5. http://doi.org/10.1039/B108504M

Vukusic, P. and Barr, J. (2010), "Bio-inspired Design", The Optician.

Yeom, K. (2009), "Bio-inspired Self-Organization for Supporting Dynamic Reconfiguration of Modular Agents", Fourth International on Conference on Bio-Inspired Computing, Beijing, China, 16-19 Oct. 2009, IEEE. http://doi.org/10.1109/BICTA.2009.5338103 